\title{
The Reference of Australian Water Sensitive Urban Design Practice to Sponge Cities in China
}

\author{
Shu Yang, Chen Yin, Hu Jiayu* \\ School of Urban Design, Wuhan University, Wuhan, China \\ Email address: \\ y.shu@whu.edu.cn (Shu Yang), chenyin1123abby@qq.com (Chen Yin),178120029@qq.com (Hu Jiayu) \\ *Corresponding author
}

\section{To cite this article:}

Shu Yang, Chen Yin, Hu Jiayu. The Reference of Australian Water Sensitive Urban Design Practice to Sponge Cities in China. Science Discovery. Vol. 7, No. 3, 2019, pp. 182-187. doi: 10.11648/j.sd.20190703.19

Received: April 23, 2019; Accepted: May 21, 2019; Published: June 15, 2019

\begin{abstract}
Water Sensitive Urban Design (WSUD) is a spatial design method which integrates urban design and urban hydrological management. Under the current background of sponge city construction, it promotes the collection, treatment and recycling of rainwater by optimizing the urban material space form, reducing the impact of urban development on natural water circulation system. Water-sensitive urban design was introduced in Australia earlier, and remarkable results have been achieved in design methods and planning practice. Taking WSUD in Australia as an example, this paper elaborates the urban design strategy based on water sensitivity, and draws lessons from Australia's experience in integrating water sensitivity design into practical design and construction at various levels, such as policy, concept, space and technology, in order to provide useful ideas for the construction and development of sponge cities in China and related research in the field of urban design.
\end{abstract}

Keywords: Water Sensitive Urban Design, Sponge City, Stormwater Management, Australia

\section{澳大利亚水敏性城市设计实践对中国海绵城市的启示}

\author{
舒阳, 陈银, 胡嘉渝 \\ 武汉大学城市设计学院, 武汉, 中国
}

邮箱

y.shu@whu.edu.cn (舒阳), chenyin1123abby@qq.com(陈银), 178120029@qq.com(胡嘉渝)

摘要：水敏性设计（Water Sensitive Urban Design, 简称WSUD），是一种整合城市设计与城市水文管理的空间设计方 法。在当前海绵城市建设背景下, 它通过优化城市物质空间形态, 减少城市开发对自然水循环系统的影响, 促进雨水 的收集、处理和循环利用。澳大利亚较早引入水敏性城市设计, 并在设计方法和规划实践方面都取得了较为显著的成 果。本文以澳大利亚的WSUD为例, 深入阐述基于水敏性的城市设计策略, 借鉴澳大利亚将水敏性设计在政策、观念、 空间、技术等多个层面整合运用到实际设计和建设中的经验, 为我国海绵城市的建设和发展及城市设计领域的相关研 究提供有益思路。

关键词: 水敏性城市设计, 海绵城市, 雨洪管理, 澳大利亚 


\section{1. 引言}

水敏性城市设计（WSUD）最早由澳大利亚学者于 二十世纪九十年代提出, 经过不断探索, 在一些较早开 展实践应用的地区, 如墨尔本、新南威尔士等, 已形成 较系统的WSUD实施指南, 并在设计方法和规划实践方 面取得了较显著的成果。这些成功的实践经验对我国正 在建设的海绵城市的发展具有较强的指导意义。尤其在 当前我国海绵城市建设背景下, 面对快速城市化进程中 层出不穷的各种城市水问题 (如内涝、缺水、水污染等), 水敏性城市设计可以通过优化城市物质空间形态，促进 雨水收集、处理和循环利用, 为减少城市开发对水循环 系统的影响提出综合性解决方案。本文将以澳大利亚的 WSUD实践为例, 剖析总结水敏性城市设计在政策、观 念、空间、技术等多个层面的实践特征, 探讨其对我国 海绵城市建设的启示。

\section{2. 澳大利亚的水敏性城市设计（WSUD）理念 的提出和发展}

20 世纪 60 年代至 90 年代, 澳大利亚的城市水管理主 要针对污水治理及水的娱乐性开发问题。90年代末, Whelan 和Halpern Glick Maunsell 首次提出WSUD理念, 这一理念以水循环为核心, 通过兼顾景观与生态环境的 复合性规划设计与综合性管理, 打破传统的单一模式, 将雨水、污水、供水等作为城市水循环系统的重要组成 部分, 进行整体考虑和统筹安排, 确保城市雨水管理、 水循环利用能够顺应自然生态的水循环过程。这一理念 也包含一系列旨在最小化或避免城市化对天然水体潜 在污染威胁的环境影响和减少城市居民对水的需求的 措施。在该理念发展初期的近 10 年的时间内, 这一理念 逐渐普及并进行利用, 从以排污为主的雨水观念转向为 对雨水的收集和利用为主。进入 21 世纪后, 澳大利亚 WSUD理论进入跨越式的发展时期, 并在墨尔本和新南 威尔士等地区开展了WSUD项目实践。这一时期从传统 的“以排为主”转变为可持续的雨洪管理模式。此后, WSUD 发展日趋成熟, 在澳大利亚多个地区（如 Melbourne[10]、) 出台了本地化的《水敏性城市设计导 则》，对雨洪管理的公众政策、方法、流程、以及评估 等进行了较为系统的整理和规范。导则陈述了城市管理 者对本地WSUD项目实施的目标期望, 并详细说明了信 息监管注意事项以及在规划设计、施工维护方面的规范 性的流程和要求, 为WSUD项目的实施提供了有力的保 障。此后，澳大利亚WSUD在政策、观念、空间和技术 方面都更加成熟。政府部门在政策层面制定WSUD设计 导则和相关规定, 充分调动当地群众的积极性, 鼓励多 方参与; 挑选试点区, 展示建设成果, 转变群众对水资 源的传统观念, 形成雨水可持续利用的新观念; 在城市 空间和WSUD技术层面上探索更合理的雨水花园的实 施方案, 更大范围的管理雨水。

\section{3. 澳大利亚WSUD实践特征及相关案例研究}

\section{1. 政策层面：协调政策支持并鼓励多方参与}

澳大利亚WSUD政策由墨尔本水务局即雨洪管理的 主管部门从设计阶段到施工阶段以及后期监管阶段总体 把控。WSUD雨洪项目是由当地政府部门在各个阶段严格 把控、监督和管理，再交由各个州的第三方进行建设和设 计的。WSUD的初期阶段建设方和委托方要进行可行性研 究并提交项目雨洪管理总体规划, 规划内容包括城市洪涝 灾害、基地水体水质现状, 以及未来的成果愿景。在随后 的初步设计、详细设计, 施工图设计等各阶段中, 建设方 必须及时将主要技术图纸交给主管部门, 以便审核。即便 进入施工阶段后, 主管部门也要对WSUD项目进行多方位 的监督和审查。不仅是政府部门和开发商参与其中, 开发 商也必须向居民说明如何将WSUD应用于城市开发或当 地的水循环利用和修复项目, 如果居民对项目存在疑虑对 项目提出质疑, 开发商要根据实际情况提出解决方案。

澳大利亚WSUD政策的实施是至上而下的, 不仅是开 发商和建设方的参与, 也有当地民众的参与, 并充分考虑 当地居民的实际需求。主管部门的监督和审核也不仅停留 在对建设方的设计原则管控上, 同时也在施工过程中采取 实地考察等方式进行严格把控, 在后期维护和服务中不断 收集各种水质、水量数据, 检查是否达到预期雨洪管控效 果。

\section{2. 观念层面: 将水作为一种资源, 系统整合利用水资 源}

墨尔本城市水循环主要考虑三类水（饮用水、废水、 雨水) 的综合管理, 实行饮用水保护, 废水最小化, 雨水 管理。三大水类都有独立的水系统, 饮用自来水系统、排 污系统和雨水系统。这些独立的水系统为澳大利亚的雨水 回收利用提供了良好的设施基础。雨水回收后通过后期的 技术处理达到一定的使用标准后进行再利用, 根据不同的 水质标准将水用于饮用或者是家庭的热水系统, 例如冲则 和淋浴。

无花果小区作为澳大利亚最早一批整合利用WSUD 技术的实际案例, 具有很大的借鉴意义。无花果小区原为 澳大利亚纽卡斯尔的一个公交车站, 大量碳氢化合物和含 油物质使该地区的地表水环境受到了严重污染。因此政府 对该地区的水资源做了重新规划, 既要考虑当地污水处理 问题, 又要考虑如何将水资源进行回收和再利用。

水回收: 无花果小区首先为了减少暴雨的地表径流, 减少雨水对设施的压力, 将受污染的土层除掉, 填上好土, 修建蓄水池搜集屋顶雨水。收集的雨水经过处理后流入地 下, 具体过程如图1所示。

水处理: 整个小区采用综合监测系统 (人工监测和自 动监测两种形式结合的系统) 对收集的雨水雨量、水质数 据进行实时监测和记录, 确保水质、水量安全, 同时对设 备维护情况进行评估。监测数据结果表明, 经过蓄水池的 沉降和处理, 水质完全达到洗浴标准, 而且温度在 $55^{\circ} \mathrm{C} \sim$ 
$63^{\circ} \mathrm{C}$ 之间的水质达到了澳大利亚饮用水标准, 水处理过程 十分成功。

水再利用: 经过处理后的雨水用于家庭热水系统、马 桶冲洗和当地的灌溉系统, 但不用于饮用。当地雨洪管理 项目提高了水的供应量, 极大的改善了当地供水紧张的状 况。同时公交车站管理公司也看到了小区雨洪管理项目的 前景, 也加入进来联合开发该地区的雨水资源, 从而解决 清洗车辆的用水问题。

通过采用雨水再利用手段, 无花果小区雨水的再利用 与普通的住宅开发相比节水总量显著, 节水总量达到了
$60 \%$ 。节省了小区约 $50 \%$ 的室内热水和冲洗则所用水, $100 \%$ 满足了花园灌溉及公共汽车清洗需求。

无花果小区的成功案例得益于该地区对水资源的重 视以及该地区居民对雨水管理项目的支持。同时澳大利亚 独立的水系统也给雨水的再利用提供了很大的帮助, 将饮 用水和家庭热水系统分离开, 降低了居民对雨水安全问题 的担忧, 也给不同的雨水水质提供了不同的处理要求, 以 达到使用目的, 一定程度上也降低了雨水处理难度和处理 成本。

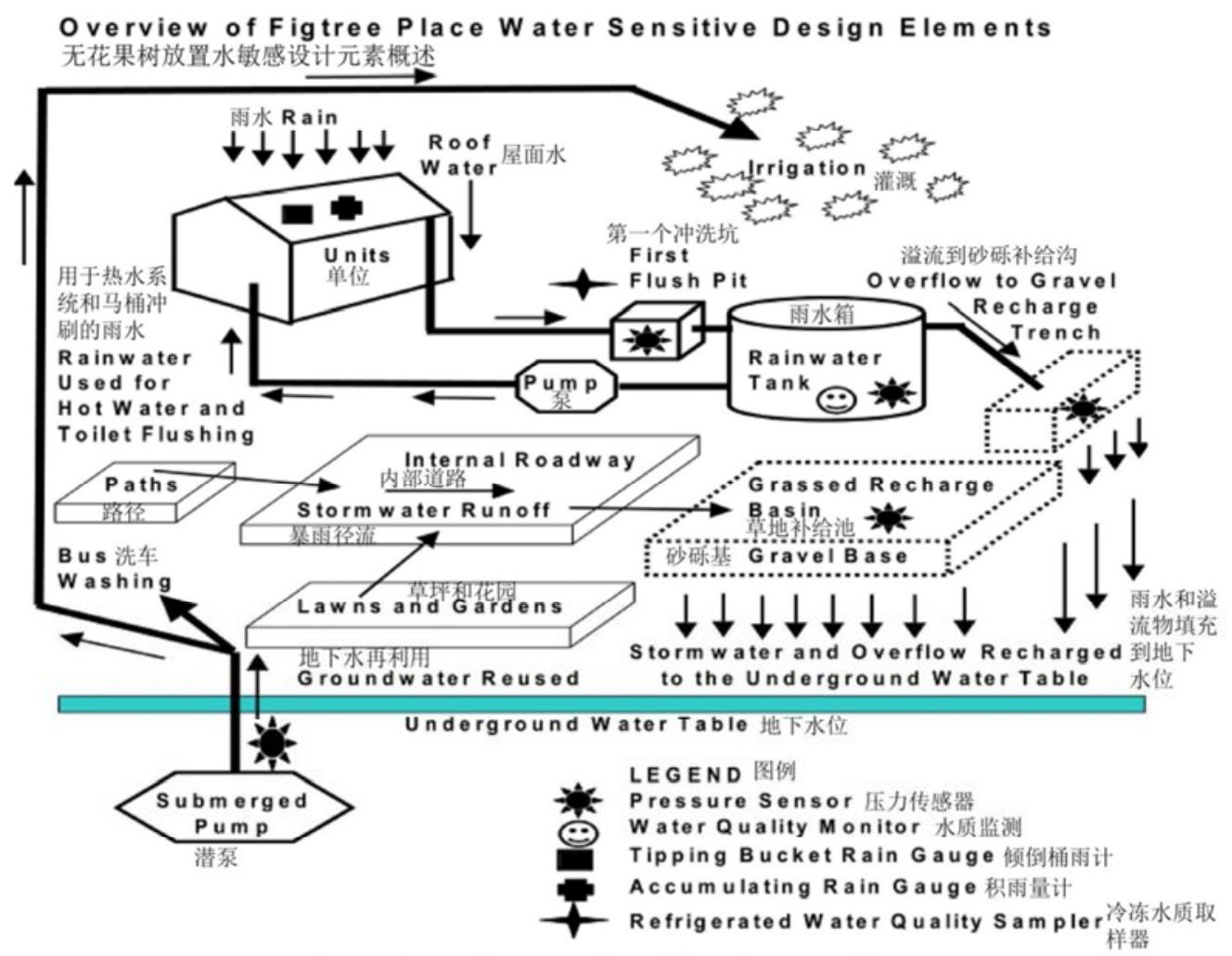

图1 无花果小区水敏感设计概念图（图片来源：作者整理）。

\section{3. 空间层面: 以公共开放空间为核心进行场地优化设 计}

公共开放空间是收集和改善水环境的主要空间地带。 例如在道路尽端设置雨水收集装置收集雨水径流, 开放马 路牙并在周边设置绿化带收集雨水; 停车场使用植草砖等 透水性地面增加雨水下渗面积; 公园绿地设置雨水花园改 善区域水环境等等。开放空间作为雨水径流的载体, 在雨 水收集、净化、存储、再利用方面潜力很大, 特别是绿地 空间。开放绿地空间的雨水下渗能力相对较好, 减缓了雨 水的地表径流速度, 使场地内的雨水尽可能下渗到地下, 对流入地下管道的雨水进行分流，减小管道压力。同时 WSUD所创造的丰富的绿地空间也可以带来不同的景观 体验。

墨尔本皇家公园一直以来都为保存当地残存的本土 植物、各种水生动物包括濒临灭绝的物种提供栖息地。特 林沃伦·坦布尔湿地（Trin Warren Tam-boore wetlands）位
于墨尔本中心城市以北 4 公里处的皇家公园西北角的一个 湿地。为了更好的保护当地生物的多样性, 政府决定对这 块普通的湿地区域进行优化设计，使这5公顷的湿地可以 从周围的郊区收集雨水, 并对雨水进行处理以满足皇家公 园内部的雨水灌溉, 为当地的动植物提供适宜的栖息地。 水滞留: 湿地开端设置淤泥沉积地和导流堰, 使雨水 在地下分流并改道减速进入“S”形处理池。“S”形这个特殊 的形态在不规则的用地上用最小的空间营造了最大的水 流距离, 使雨水中的较大沉积物得到沉淀, 同时用最少的 空间开发减少了对周边皇家公园的影响。“S”形这个曲折 的形态也在一定程度上减缓了水流的速度, 增加雨水沉淀 时间, 泥沙和垃圾就会脱落, 一些中等的甚至细小的沉积 物得以沉淀, 留在处理池中。

水过滤: 夹杂着落叶等大型沉积物的雨水在湿地入口 处的淤泥坑进行初步沉淀, 然后后再流入“S”形处理池。 而“S”形处理池的浅水区微生物净化池, 水深只有 0.5 米, 这使得雨水可以最大限度地暴露在植物和阳光的清洁作 
用下。水池内部填上砂质黏土, 种植当地植物, 利用植物、 茎上的微生物吸收或转化氮和其他营养物质来净化雨水 （如图2）。湿地系统的“S”形水塘通过合理的高差设计最 大限度地利用重力进行水流, 减少对泵的需求, 它细长形 状和不同深度确保进入水塘的水在通往溢流口的漫长道 路上缓慢移动, 同时也最大化的减少了雨水中的大型沉积 物和小型微生物对收集的雨水水质的影响。

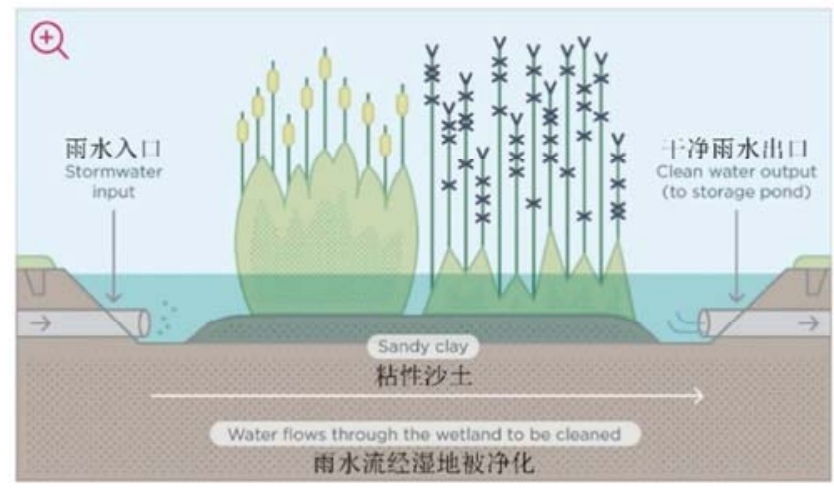

图2 生物进化池（图片来源：作者整理）。

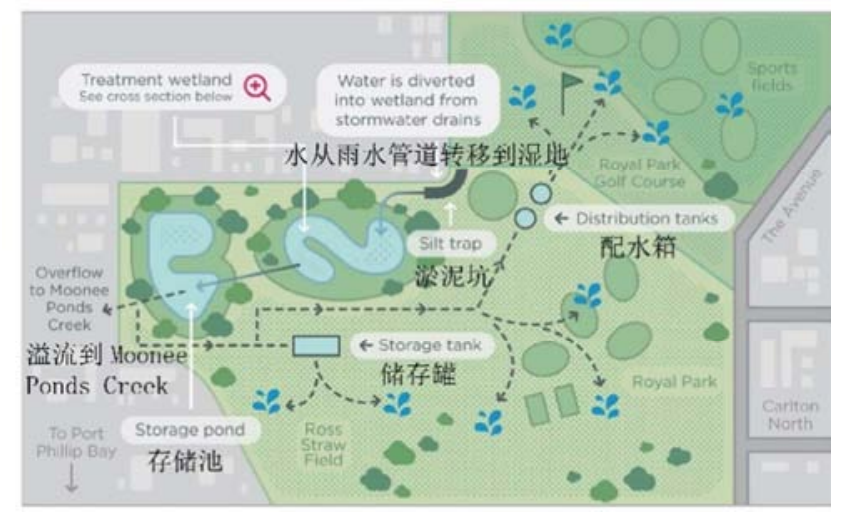

图3 雨水处理系统（图片来源：作者整理）。

水存储: 处理后的雨水出口在雨水处理池末端, 是处 理池最深的部分, 这里的水大部分通过地下管道流入到存 储池进行存储, 还有一小部分的水溢出到周边的绿地。存 储池的雨水再逐步转移到周边的存储罐和配水箱 (如图3)。
水再利用: 收集处理后的雨水出于安全考虑会通过紫 外线消毒装置进行消毒, 且仅用于公园内部的灌溉系统。 白天雨水通过控制系统将雨水分散运输到公园各处较小 的水箱中, 夜间再利用循环用水进行灌溉, 多余的水被返 回到排水系统。通过每天将水逐渐转移到公园的不同区域, 整个湿地系统的雨水得到了充分的利用。湿地回收的雨水 用于公园的灌溉系统, 极大的减少了用于植物灌溉的饮用 水。

公园景观绿化: 湿地拥有复杂的生态系统, 为各种动 植物提供了富含食物和养分的繁殖地。整个池塘区域成为 当地水鸟和昆虫以及水生物栖息的主要场所。而湿地水塘 设置的多样化人形步道和栖息地群岛, 增加了水塘的趣味 性并丰富了当地生物物种的多样性。公园里丰富的植被和 湿地类型, 以及阶陌交通为游客提供了丰富的空间、教育 和休闲体验。

\section{4. 技术层面: 采用多样化绿色基础设施技术手段, 兼 顾景观文化功能}

澳大利亚WSUD在宏观、中观、微观等多个尺度都运 用了可持续的水管理技术。对公共开放空间、街道、道路 节点进行了详细设计, 对不同尺度和功能的场地在雨水收 集、处理与再利用方面采用多样化的绿色基础设施和技术 手段。

公共开放空间: 开放空间主要以场地优化为主, 例如 澳大利亚的典型案例爱丁堡公园。首先为了收集公园内的 雨水在公园内部设置排水沟, 将雨水导入到公园的沉降池, 再通过快速沉降去除河床中的沉积物和一些悬浮物, 对雨 水进行初次过滤。再设置梯田式雨水花园, 利用梯田式的 植被景观改善水流方向, 利用重力自然净化雨水, 同时对 雨水中的微量元素及污染物进行消解。最后将经过处理的 雨水存储在集水箱, 用以灌溉周边的公园树木。整个水循 环利用过程（如图4) 中, 集水阶段和初步沉降阶段利用 灰色设施进行处理以及最后的水存储阶段都利用了灰色 设施, 而在雨水净化阶段利用了绿色设施, 这种灰绿结合 的水处理手段改善了当地的用水环境, 满足了公园内部的 灌溉用水。

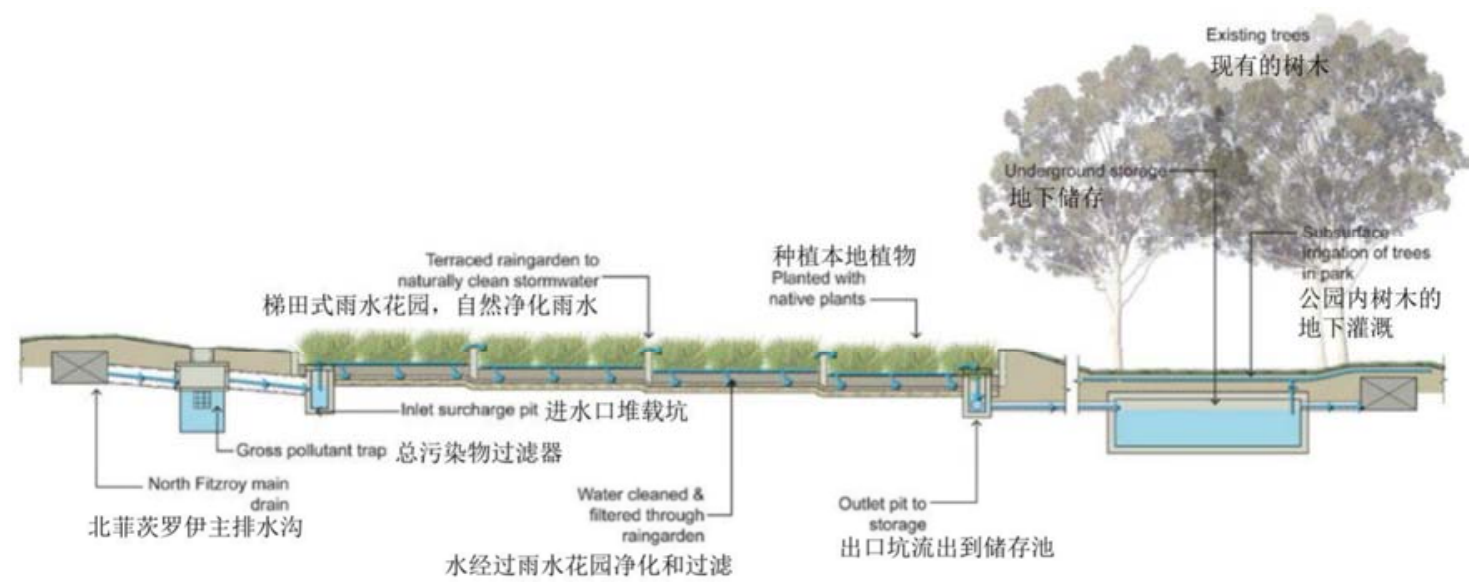

图4 雨水花园经典案例：-爱丁堡雨水花园剖面图（图片来源：作者整理）。 
道路: 澳大利亚WSUD技术在城市交通负荷较小的区 域, 如人行道和停车场铺筑多孔铺装（或透水铺装、植草 砖）代替不透水路面, 使得径流可以渗入土壤或下面的专 用蓄水库。将马路牙局部打开, 使道路雨水集中在道路绿 化带, 道路的透水性路面和绿化带过滤、拦截和生物处理 污染物, 保护水体受到污染。同时在道路尽头设置雨水花 园, 并与道路形成高差, 最大限度的收集道路雨水。这种 处理方式解决了传统人行道较狭窄、路面材料不透水, 雨 水花园的建设和植物的种植受限和车行道受到汽车尾气 和金属化合物的污染, 道路上的雨水受到大面积污染, 雨 水滞留在道路上形成雨水坑的问题。

街区节点：建筑立面上安装水落管，周边人形道上种 植树池。行道树的设计可以将雨水径流从屋面和街道转移 到道路上的树池中, 并通过植被介质过滤, 然后排入雨水 系统。同时利用水落管收集的雨水灌溉植物, 减少植物灌 溉对饮用水的需求, 并提高土壤湿度 (如图5)。墙体周 围设置植物洼地和缓冲带, 植被洼地用来代替管道输送雨 水，并在集水区和不渗水区域之间提供“缓冲”。同时植被 洼地可以和公园等景观结合设计, 弱化建筑硬边界, 改善 绿化环境, 提高街道的使用率, 增加城市的适宜空间。

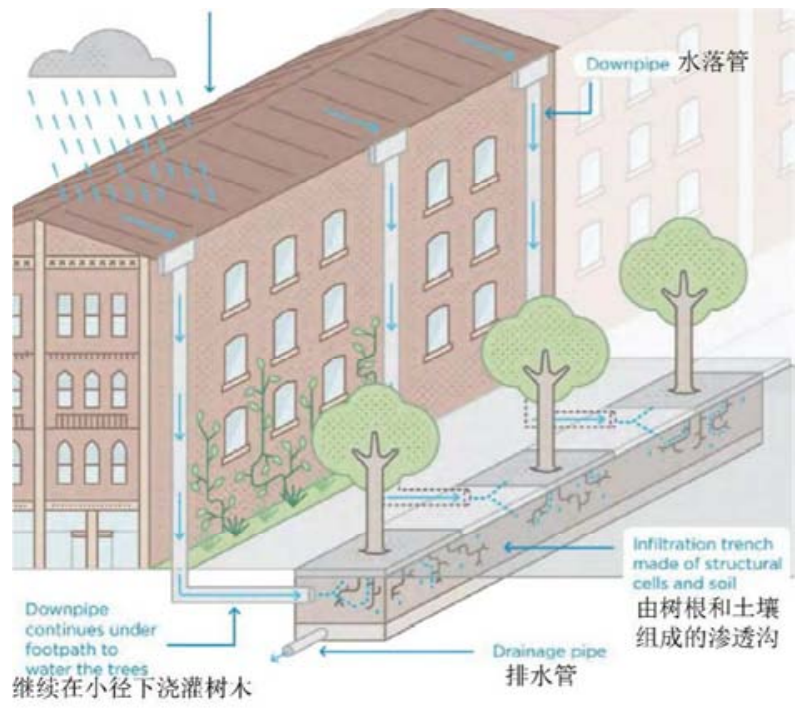

图5 建筑周边雨水处理（图片来源：作者整理）。

\section{4. 结论: 澳大利亚WSUD实践对中国海绵城市 建设的启示}

澳大利亚水敏性城市设计（WSUD）通过将雨洪管理 和城市设计相结合, 创造出了更适宜的城市城市景观和城 市水环境系统, 对中国当前的海绵城市建设有重大借鉴意 义。澳大利亚的一系列WSUD项目通过颁布政策、出台指 导性设计导则、鼓励社区群众参与、整理城市水环境和城 市公共开放空间的重要联系、以及合理利用和导则相匹配 的多样化的绿色技术手段, 在区域水环境改善方面进行了 有益的探索并取得了积极的成效。澳大利亚的WSUD实践 经验也为中国提倡生态、绿色、美好的海绵城市建设提供 了新的思路，简要概括为以下四个方面。

\section{1. 政策层面}

澳大利亚的水敏性城市设计一直都有相关制度和法 律法规的支持与维护，在全国性指导原则文件的基础上， 根据各个地方不同的地理条件和水环境出台地方性的详 细的指导原则文件, 包括设计要求和相匹配的施工技术等。 从政府决策阶段到设计阶段再到施工阶段都考虑民众参 与, 都有相应的指导原则和相关条文对WSUD设计进行规 范和引导。中国也应该出台适用于本国相应地区管理体系 的相关法律法规体系和指导性设计文件, 在《海绵城市建 设技术指南》的基础上建立和完善相关法规与制度，切实 保障海绵城市建设的可实施性和可持续性。在标准制定上, 可以借鉴澳大利亚近几十年的发展经验, 首先在政策层面 推行指导性设计原则文件和技术指南, 然后发展具有地域 特色的推荐性、地方性标准，同时考虑目标结果及最终奖 罚制度, 出台强制性标准。

\section{2. 观念层面}

澳大利亚的WSUD实践将 “以排为主”的传统雨水管 理观念转变为将雨洪管理与城市设计及景观设计结合考 虑的理念, 减少了城市空间发展对自然水循环、水生态平 衡的影响, 建立了综合性的带有地方特色的可持续雨洪管 理模式。这一发展理念值得中国学习借鉴。

另一方面，澳大利亚各地居民将雨水回收处理后用于 家庭热水系统, 将回收水作为一种可循环利用的水资源对 待已成为一种较普遍的现象。中国也应该通过示范案例和 宣传教育相结合的方式, 积极加强对水资源的宣传教育, 尤其可以在学校等教育机构对青少年及儿童开展水资源 教育; 通过广泛教育提高广大居民对水资源的全面认识, 强调雨水回收、处理、再利用的重要性, 加强居民的节水 意识。居民是政策的最终受益者, 要充分调动居民的积极 性, 在积极推行雨污分离的同时宣传家庭节水意识, 使居 民自觉参与到海绵城市建设中, 根据他们自身最真实的需 求来制定设计策略, 保证各项策略的正常进行和实施。

\section{3. 空间层面}

澳大利亚一系列成功的WSUD案例, 充分展示了公共 开放空间在城市雨洪管理和水环境营造中所发挥的关键 作用和巨大潜力。公共开放空间以其更开阔的空间形式、 更丰富的下垫面选择、更有效的实施保障, 为雨水的收集、 净化、过滤提供了多样化的解决方案。澳大利亚WSUD设 计在公共开放空间的处理上通过优化场地设计增加可透 水面积, 并将景观设计与雨洪管理充分结合, 综合考虑场 地内的水资源利用、景观美化和社会功能。比如在墨尔本 皇家公园案例中，“S”形水塘不仅成为场地内的一大景观 特色, 也给生物降解提供了有利空间。

在中国的海绵城市建设中，公共开放空间营造的试点 和示范作用也不容忽视。尤其在空间优化设计中, 不仅要 考虑水敏性量化指标的落实（如年径流总量控制率等）, 更要将对水环境的考虑与整体空间设计概念相结合, 从空 
间构成要素的形态、关系、尺度、材质等多方面细致分析， 综合发挥空间的功能、景观、环境效益。

\section{4. 技术层面}

澳大利亚水系统已实行雨污分离, 这在很大程度上 降低了水资源再利用的难度。在独立的雨水处理系统基 础上，澳大利亚WSUD技术在宏观、中观、微观等多个 场地尺度和不同功能地块上采用例如雨水花园、绿化沉 降池、植草沟、树坑、高位花园等与场地相匹配的技术 手段, 而非单一使用灰色雨水导流设施进行雨水排污设 计。同时利用微生物降解净化雨水, 再通过水管进行导 流，灰绿结合的方式净化雨水。在中国的海绵城市建设 中, 也应围绕渗、滞、蓄、净、用、排等雨水调控的关 键步骤，将市政管网建设同发展绿色基础设施相结合; 根据具体场地环境、水文特征、经济条件等, 合理选用 水敏性开发技术及其组合系统。同时, 对绿色基础设施 的考虑还要兼顾其空间效果和景观文化功能, 使雨洪管 理与城市设计的结合落实到技术细节。

\section{致谢}

感谢国家自然科学基金《基于弹性城市理论的水敏性 空间设计方法研究一以武汉市为例》项目 (中国) (51508422)和武汉大学通识课项目 (中国) (413200041) 给予资金的支持。

\section{参考文献}

[1] 刘颂,李春晖.澳大利亚水敏性城市转型历程及其启示 [J].风 景园林,2016(06): 104-111。

[2] 刘雅睿.水敏性城市设计初探--以伊洛河水生态文明示范区 东北区景观设计为例[D].河南大学,2016: 1-45。
[3] 俞孔坚,李迪华,袁弘,傅微,乔青,王思思.“海绵城市”理论与 实践 $[J]$.城市规划,2015,39(06): 6-36。

[4] 冀紫钰.澳大利亚水敏感城市设计及启示研究[D].河北工程 大学,2014: 1-74。

[5] 高洋.水敏性城市设计在我国的应用研究[D].哈尔滨工业大 学,2012: 1-96。

[6] 王鹏.(澳大利亚)吉露·劳森. 刘滨谊. 水敏性城市设计 (WSUD)策略及其在景观项目中的应用[J].中国园林, 2010, 26 (6) : 88-91.

[7] 夏镜朗, 崔浩.澳大利亚水敏性城市设计经验对中国海绵城 市建设的启示[J].中国市政工程,2016, (4): 36-40。

[8] 海绵城市建设技术指南-低影响开发雨水系统构建 [Z].住房 与城乡建设部, 2014。

[9] Peter J Coombes,John R Argue, George Kuczera.Figtree Place: A Case Study in Water Sensitive Urban Development(WSUD) [J]. Urban Water, 2000, 1 (4): 335-343.

[10] Melbourne Water. City of Melbourne WSUD Guidelines: Applying the Model WSUD Guidelines [Z], Melbourne,Australia: Melbourne water, 2010.

[11] Trin Warren Tam-boore wetlands [Z]. City of Melbourne Urban Water.

http://urbanwater.melbourne.vic.gov.au/projects/wetlands/wetl ands-sample-project/.

[12] Godfrey Street greening [Z]. City of Melbourne Urban Water.http://urban water.melbourne.vic.gov.au/projects/wetlands/wetlands-sampl e-project/.

[13] 胡嘉渝, 范晓辉, 舒阳.The Reference of Singapore ABC Water Plan to China's Sponge City: A Case Study of Singapore Interlaced Building [J]. Science Discovery, 2018: 6 (6): 471-476. 